\title{
Cross-cultural adaptation and validation of the episodic autobiographic memory interview for Brazilian Portuguese
}

\author{
Validação e adaptação transcultural da entrevista para avaliação da memória episódica \\ autobiográfica para o português brasileiro
}

Guilherme R. Rodrigues, Daniel S. Oliveira, Maria P. Foss, Osvaldo M. Takayanagui

\begin{abstract}
Episodic memory enables the storage of personal events with specific temporal and spatial details, and their retrieval through a sensory experience, usually visual, which is called autonoetic consciousness. While, in Brazil, several scales for the evaluation of anterograde episodic memory have been validated, there is not yet an instrument to assess the episodic autobiographical memory. The aim of this study is thus to make a cross-cultural adaptation and validation of the Episodic Autobiographic Memory Interview (EAMI) for Brazilian Portuguese. Altogether, 11 patients with Alzheimer's disease (AD) and 10 healthy controls (CTs) were evaluated. EAMI scores for AD patients were lower than those of CTs, and these scores also correlated positively with the Remember-Know coefficient. The intraclass correlation coefficient indicated a good inter-rater reliability. The Portuguese version of EAMI showed a good reliability and validity, which suggests that it is a useful tool for evaluation of autobiographical memory in Brazilian patients.
\end{abstract}

Keywords: episodic memory, autobiographical memory, Alzheimer's disease.

\section{RESUMO}

A memória episódica possibilita o arquivamento de eventos pessoais, com seus detalhes temporais e espaciais, e sua recuperação através de uma experiência sensorial, geralmente visual, chamada de consciência autonoética. No Brasil, foram validados vários instrumentos para avaliação da memória episódica anterógrada, porém não há ainda uma escala para avaliar a memória episódica autobiográfica. 0 objetivo deste estudo é realizar uma validação e adaptação transcultural da Entrevista para avaliação da Memória Episódica Autobiográfica (EMEA) para o português brasileiro. Onze pacientes com doença de Alzheimer (DA) e 10 controles normais foram avaliados. Os escores dos pacientes com DA na EMEA foram menores do que nos controles saudáveis. Estes escores se correlacionaram positivamente com o coeficiente Lembrar-Saber. O coeficiente de correlação intraclasse indicou uma confiabilidade inter-examinadores adequada. A EMEA demonstrou uma boa validade e confiabilidade, sugerindo que ela é um instrumento útil para a avaliação da memória autobiográfica em pacientes brasileiros.

Palavras-Chave: memória episódica, memória autobiográfica, doença de Alzheimer.

Memory is defined as the ability to archive information and make it available for later retrieval, which allows the mind to draw upon previous experiences during decision-making ${ }^{1}$.

There are several memory systems, classified in accordance with clinical and neuroanatomical features that have become known in recent decades. Working memory refers to the ability to consciously retain information for about $60 \mathrm{sec}-$ onds ${ }^{2}$. Procedural memory enables connections to be made between complex stimuli and motor responses, such as the ability to play the piano or play tennis, for example ${ }^{3}$. Semantic memory is the ability to archive general information, allowing an individual to build mental models of the world, such as knowing the face of a former president or remembering the capital city of a given country ${ }^{4}$. Episodic memory allows for the storage of personally experienced events, with their specific temporal and spatial occurrences ${ }^{5}$ and subsequent recall through a sensory experience, usually visual, which is called autonoetic consciousness ${ }^{5}$.

The way that declarative memories (i.e. semantic memories and episodic memories) are stored in the brain is still under debate. The "Standard Model of Memory Consolidation" affirms that memories are initially stored in the hippocampus and, over time, are transferred to the cerebral cortex. Consequently, patients with hippocampal injury would lose only the most

Universidade de São Paulo, Faculdade de Medicina de Ribeirão Preto, Departamento de Neurociências e Ciências Comportamental, Ribeirao Preto SP, Brazil. Correspondence: Guilherme R. Rodrigues; Hospital das Clínicas de Ribeirão Preto; Campus Universitário s/n; 14048-900 Ribeirão Preto SP, Brasil; E-mail: ggrr@usp.br Conflict of interest: There is no conflict of interest to declare.

Received 26 November 2014; Received in final form 15 February 2015; Accepted 06 March 2015. 
recent declarative memory, leaving long-term memories intact ${ }^{6}$. However, overwhelming evidence suggests that patients with hippocampal lesions experience a predominant loss of episodic memory with little involvement of semantic memories $^{7}$, which has led Nadel and Moscovitch ${ }^{8}$ to develop a new model for memory consolidation, known as the "Multiple Trace Theory" (MTT). According to the MTT, semantic memories are progressively transferred to the neocortex and episodic memories are always stored in the hippocampus.

Although further studies corroborate the anatomical distribution advocated by the $\mathrm{MTT}^{9}$, this theory cannot yet explain how episodic memories are stored in the hippocampus. For example, anterograde episodic memories and episodic autobiographical memories may be stored differently.

Newly amnestic syndromes in epileptic patients have revealed a dissociation between anterograde and autobiographical episodic memories, namely in Accelerated Long-term Forgetting ${ }^{10}$ and Transient Epileptic Amnesia ${ }^{10}$. In both these conditions, patients often have normal anterograde episodic memory with frequent impairment of autobiographical memory ${ }^{10,11}$. Recently, Coras et al. ${ }^{12}$ have demonstrated that hippocampal sclerosis patients with greater neuronal loss in CA3, CA4 and the dentate gyrus have a predominant loss of anterograde memory, and that, conversely, those with predominant neuronal loss in CA1 generally have normal anterograde memory. These findings suggest that intra-hippocampal anatomical regions may be associated with specific subtypes of episodic memory.

In Brazil, there are several tests to assess anterograde episodic memory, such as the Rey Auditory Verbal Learning Test ${ }^{13}$, and the Memory of Figures Test (MFT) ${ }^{14}$. However, there is not yet a validated instrument for the study of episodic autobiographical memory. The aim of this work is therefore to translate, adapt and validate the Autobiographic Episodic Memory Interview $(\text { EAMI })^{15}$ in a population of Brazilian amnestic patients.

\section{METHOD}

\section{Selection of patients}

Participants were healthy controls or patients with $\mathrm{AD}$, diagnosed according to the National Institute on Ageing and Alzheimer's Association Criteria ${ }^{16}$ who attended the Behavioral Neurology Service of the Hospital das Clinicas de Ribeirao Preto. Participants who fulfilled one or more of the following items were excluded from this study: 1) Presence of depressive symptoms, characterized by a score of five or more on Geriatric Depression Scale ${ }^{17} ; 2$ ) evidence of cerebrovascular disease, confirmed by a score of four or more in the Hachinski Ischemic Score ${ }^{18}$ or neuroimaging suggestive of cerebrovascular damage; 3 ) history of excessive alcohol intake; 4) presence of Parkinsonism; 5) age lower than 65 years; 6) schooling of less than 2 years; and 7) use of medications that could potentially interfere with cognitive abilities.

\section{Neuropsychological assessment}

Participants global cognitive status was assessed using the Mini-Mental State Examination ${ }^{19}$. Anterograde episodic memory was estimated using the $\mathrm{MFT}^{14}$. The semantic verbal fluency test and clock drawing test ${ }^{20}$ were used to evaluate executive function/language and visuospatial abilities, respectively. Direct and backward digit span tests were used to assess attention and working memory. The Geriatric Depression Scale ${ }^{17}$ was employed to assess the presence of depressive symptoms. The Functional Activities Questionnaire $(\mathrm{FAQ})^{21}$ and $\mathrm{AD}-8^{22}$ were completed by a caregiver, and the results were used to quantify functional impairment and assess their perception of patients' cognitive status. Finally, we applied an adapted version of the Remember-Know paradigm ${ }^{5}$.

Briefly, we presented a sequence of 20 pairs of words constituted of a target and its categorical classification (e.g. Saturn-Planet), and asked participants to memorize the target for a subsequent test. These dyads were presented one by one, each for a duration on 5 seconds using an automatic projection of PowerPoint ${ }^{\circ}$. Using the clock drawing test as a distractor, participants were asked to freely recall the target words (spontaneous recall). After each answer, participants were asked if they remembered the exact moment that the word was presented (a Remember answer) or simply knew that the word was that (a Know answer). Following this, participants were presented with categorical words only, and were encouraged to say the associated target word (assisted recall). Again, this was followed by a Remember-Know question procedure. We calculated the Remember-Know coefficient $(\mathrm{RKc})$ by subtracting the wrong "Remember" responses by the correct "Remember" answers and dividing this figure by the total number of words presented.

\section{EAMI adaptation and validation process}

The EAMI $^{15}$ is a semi-structured interview that aims to evaluate autobiographical memory, notably its episodic component. The EAMI is divided in 3 parts: 1) Personal Semantics (names of people, daily living, an important date); 2) Autobiographical Event Recall (event detail, temporal specificity, sensory/perceptual detail, spatial specificity, emotion, implication, thoughts); and 3) Autonoetic Awareness Assessment. This last part is entirely qualitative and is subdivided in 5 multiple choice items: 3.1 ) Perspective (own eyes; third person's perspective; neither; no image); 3.2 ) Continuity (do the images follow in sequence with no gaps in between?; How would you describe the event as it appears in your mind's eye?); 3.3) Rehearsal (have you thought/spoken about this event since it occurred? frequently; occasionally; rarely; never); 3.4) Emotional Connection (when you remember this event, do you re-experience the same emotions as you felt at the time? $0 \% ; 25 \% ; 50 \% ; 75 \% ; 100 \%$. do you feel any physical trace of this emotion?); and 3.5) Recollective Experience (would you say you are reliving what happened? or are you more like an observer looking back on the event? 
to what extent do you feel you are re-experiencing the memory? $0 \% ; 25 \%$; $50 \% ; 75 \%$; $100 \%)$.

The EAMI is scored according to memories provided by the patient across the lifespan, from Childhood (0-15 years), to Early Adulthood (16-30 years), to Middle Adulthood (31-45 years), to Later Adulthood (46 years, up to 5 years ago) to Recent memory (in the last 5 years). The EAMI score is the sum of Personal Semantics and Autobiographical Events points, and the maximum score is 105 .

The process of translation and cultural adaptation of the EAMI was prepared according to the recommendations provided by Beaton et al. ${ }^{23}$ Two native Portuguese speakers with English fluency independently translated the EAMI. Through a comparison of both versions, a consensual version was created. This version was then back-translated into English by two English teachers, who then created a consensual English version that was re-evaluated with the authors of the first translation to achieve a final version in English. Next, this was sent to the author of the scale (Muireann Irish, PhD), who suggested some changes and ratified the final version.

The inter-rater reliability of EAMI was measured by a second evaluation of 15 randomly selected individuals, using audio recordings of the original interviews. The second examiner was unaware of the patients' diagnosis and received only written instructions of the scale. The intraclass correlation coefficient was employed to measure the degree of agreement between the scores. The reliability coefficient Cronbach's $\alpha$ was used to measure the internal consistency of the EAMI. The RKc was used as the main measure of construct validation, since it has been considered the best way to classify memories as episodic or semantic ${ }^{5}$.

\section{Statistical analysis}

It is necessary to obtain data from 9 participants on each arm in order to achieve a 1.5 standard deviation difference between amnestic and control scores on the EAMI, with a type 1 error of $5 \%$ and type 2 error of $20 \%$.

All results were analyzed for normality of distribution by the Shapiro-Wilk test. The presentation of data was performed using the mean and standard deviation if normally distributed, and using the median with interquartile range if non-normally distributed. Continuous variables were compared using the Student's t-Test if data was normally distributed or the Mann-Whitney test if non-normally distributed. To evaluate the influence of age and schooling on the final EAMI scores, an analysis of covariance (ANCOVA) with these items as covariates was performed. The analysis of categorical data from the Autonoetic Awareness Assessment was made using the Fisher's exact test. The degree of correlation among EAMI, RKc, and MFT were estimated by the Pearson's or Spearman's correlation coefficient, depending on normal or non-normal distribution of data, respectively. In tests in which multiple comparisons were performed, the Bonferroni correction was applied. Statistical tests were executed with
R (http://www.R-project.org) and Wizard Statistic Package (http://www.wizardmac.com) programs.

\section{Ethics}

The ethical board of the Hospital das Clinicas de Ribeirao Preto approved the research protocol (n. 1155/2012). All patients provided informed consent for participation in this study.

\section{RESULTS}

The demographic and neuropsychological data of participants are summarized in Table 1. The EAMI scores presented a good discrimination between patients and controls (Figure 1). Education and Age did not significantly influence the final EAMI score ( $\mathrm{F}=3.47, \mathrm{p}=0.08$ and $\mathrm{F}=0.7, \mathrm{p}=0.4$, respectively).

Control subjects also had superior performance to $\mathrm{AD}$ patients in all memory tests performed.

The Pearson's correlation coefficient between EAMI scores and delayed recall of the MFT was 0.84 ( $p<0.001)$; between EAMI and spontaneous and assisted recall of word list test was 0.73 and 0.83 respectively (both $p<0.001$ ); Spearman's correlation coefficient between EAMI and RKc was $0.71(\mathrm{p}<0.001)$ (Figure 2).

Table 1. Demographic and neuropsychological characteristics.

\begin{tabular}{lccc}
\hline Variable & Controls & AD & $p$ \\
\hline$n$ & 10 & 11 & \\
Age & $71.3(4.24)$ & $76.3(6.98)$ & 0.06 \\
Schooling* & $7.5(4-12.5)$ & $4(3-5.5)$ & 0.15 \\
FAQ* & 0.5 & 16 & $<0.001$ \\
& $(0-1)$ & $(12.5-20)$ & \\
AD-8 & $2.7(2.5)$ & $6.3(1.0)$ & 0.003 \\
MMSE & $27.6(1.8)$ & $23.2(2.7)$ & $<0.001$ \\
MFT & $8.8(0.9)$ & $2.2(2.4)$ & $<0.001$ \\
CDT & $8(1.6)$ & $6.1(2.4)$ & 0.06 \\
VF* & 14 & 7 & 0.005 \\
& $(11.25-19.5)$ & $(7-11)$ & \\
DS-DO & $6(1.1)$ & $5.9(1.2)$ & 0.86 \\
DS-IO & $3.6(1.3)$ & $3.4(1.2)$ & 0.79 \\
GDS-15 & $1.6(1.1)$ & $2.3(1.5)$ & 0.21 \\
SR-WLT & $4.9(2.8)$ & $0.5(0.8)$ & $<0.001$ \\
AR-WLT & $12.3(3.4)$ & $2.9(2.2)$ & $<0.001$ \\
RKc* & 0.42 & 0.05 & $<0.001$ \\
& $(0.31-0.66)$ & $(0-0.05)$ & \\
EAMI total & $88.7(8.2)$ & $56.3(13.6)$ & $<0.001$ \\
EAMI: Personal Semantics* & 62.75 & 49.5 & $<0.001$ \\
& $(61.25-64.62)$ & $(44-50.75)$ & \\
EAMI:Autobiographical events & $26.2(4.6)$ & $10.7(4.4)$ & $<0.001$
\end{tabular}

FAQ: Functional Activities Questionnaire; MMSE: Mini-mental State Evaluation; MFT: Memories of Figures Test; CDT: Clock Drawing Test; VFT: Verbal Fluency Test; DS-DO: Digit Span - Direct Order; IO: Inverse Order; GDS-15: Geriatric Depression Scale 15 items; SR-WLT: Spontaneous recall - word list test; AR-WLT: assisted recall - word list test; RKc: Remember-Know; EAMI: Episodic Autobiographic Memory Interview. *Mann-Whitney. 


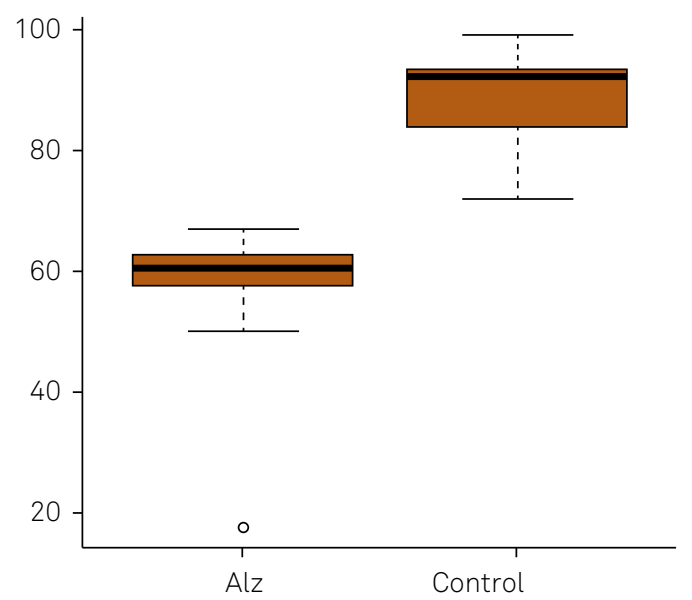

EAMI: Episodic Autobiographic Memory Interview.

Figure 1. The EAMI scores in Alzheimer's disease patients and healthy controls.

For the measures of reliability, the intraclass correlation coefficient was 0.99 on the subscale of Personal Semantics, and 0.98 in Autobiographical Event Recall. Internal consistency, measured by Cronbach's $\alpha$, was 0.73 and 0.86 respectively.

Some items of the Autonoetic Awareness Assessment subscale were also able to discriminate between $\mathrm{AD}$ patients and controls, especially in items related to the formation of visual imagery and sense of reliving the remembered event (Table 2).

\section{DISCUSSION}

This study carried out the cultural adaptation and validation of a Brazilian Portuguese version of the EAMI. We compared the performance in the EAMI with other measures of episodic memory, such as the delayed recall of the MFT, the subtests of spontaneous and assisted recall of the word list, and the RKc, from the Remember-Know paradigm. There was a strong correlation between EAMI and the episodic memory scores derived from these tests, which supports the construct validity of our Portuguese version of the EAMI.

The EAMI was able to differentiate healthy subjects from $\mathrm{AD}$ patients, both in the Personal Semantics and Autobiographical Events subscales. This finding is consistent with previous $\mathrm{AD}$ patient studies that have used other instruments for assessing autobiographical memory ${ }^{24,25,26,27}$. Despite the fact that $\mathrm{AD}$ patients in the current study were older and less educated than control group, these variables had little influence on the final EAMI score.

The ability to discriminate controls from $\mathrm{AD}$ patients was also observed in the Autonoetic Awareness Assessment section of the EAMI, in the items related to the formation of visual imagery and to the feeling of reliving the event remembered. In this study, no difference was observed between $\mathrm{AD}$ patients and controls regarding the emotional association with the recalled memory. As several studies suggest there to be a strong relationship between memory and emotion ${ }^{28}$, it is likely that

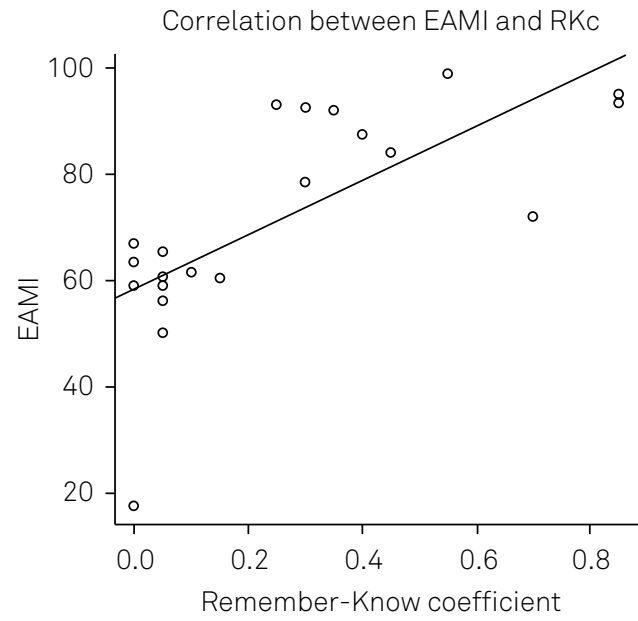

EAMI: Episodic Autobiographic Memory Interview; RKc: Remember-Know. Figure 2. Correlation between EAMI and RKc.

Table 2. Results from the Autonoetic Awareness Assessment EAMI subscale.

\begin{tabular}{lccc}
\hline & Controls & AD & $p$ \\
\hline Own eyes Perspective & $42(84 \%)$ & $12(21.8 \%)$ & $p<0.001$ \\
No image & $7(14 \%)$ & $43(78.1 \%)$ & $p<0.001$ \\
$\begin{array}{l}\text { See the memory with no gaps } \\
\text { like a video }\end{array}$ & $34(68 \%)$ & $8(14.5 \%)$ & $p<0.001$ \\
$\begin{array}{l}\text { Frequently or occasionally } \\
\text { think about this memory }\end{array}$ & $11(22 \%)$ & $13(23.6 \%)$ & $p=1$ \\
$\begin{array}{l}\text { Frequently or occasionally } \\
\text { speak about this memory }\end{array}$ & $8(16 \%)$ & $5(9 \%)$ & $p=0.38$ \\
$\begin{array}{l}\text { Emotional Connection when } \\
\text { remembering this memory }\end{array}$ & $10(20 \%)$ & $11(20 \%)$ & $p=1$ \\
$\begin{array}{l}\text { Participant feel that he is } \\
\text { reliving this memory }\end{array}$ & $23(46 \%)$ & $10(18.1 \%)$ & $p=0.003$ \\
\hline
\end{tabular}

EAMI: Episodic Autobiographic Memory Interview.

the EAMI is not an adequately sensitive tool for assessing emotional responses to the act of remembering an episodic memory. It is noteworthy that this pattern of responses is in agreement with previously published EAMI data from patients with Mild Cognitive Impairment ${ }^{29}$ and $\mathrm{AD}^{30}$.

There was a high internal consistency among the EAMI items, observed in both the Autobiographical Events and Personal Semantics subscales. We found there to be high inter-rater reliability, as revealed by strong correlations between the scores of the two examiners in both the Personal Semantics and Autobiographical Events subscales, a finding that well reflects the original publication of the EAMI ${ }^{15}$. It is important to note that the analysis of the inter-rater reliability of an instrument that assesses the occurrence of spontaneous memories requires a specific methodology, especially considering that a participants may recall different memories in different interviews and therefore receive different scores in each. With this in mind, Irish et al. ${ }^{15}$ chose for a first examiner to write the answers of each patient and for a second examiner, independent of the original session, to score these written responses. However, it is possible that, while 
writing down the responses, the first examiner may have given a subliminal indication of an item's score. For this reason, we chose to record the interview and deliver full, unedited audio to the second examiner. Additionally, this second examiner was given only written instructions on how to apply the scale, which also allowed us to test their intelligibility; the high correlation between the two examiners' thus also demonstrates that the written instructions on how to apply the scale are adequate.

In conclusion, our data suggest that the Brazilian Portuguese version of the EAMI is a valid and reliable instrument for the assessment of autobiographical episodic memory, and may be a useful tool in the evaluation of amnestic syndromes, notably those of hippocampal origin.

\section{References}

1. Tulving, E. How many memory systems are there? Am Psychol. 1985;40(4):385-98. http://dx.doi.org/10.1037/0003-066X.40.4.385

2. Baddeley AD, Warrington EK. Amnesia and the distinction between long- and short-term memory. J Verbal Learn Verbal Behav. 1970;9(2):176-89. http://dx.doi.org/10.1016/S0022-5371(70)80048-2

3. Cohen NJ, Squire LR. Preserved learning and retention of pattern-analyzing skill in amnesia: dissociation of knowing how and knowing that. Science. 1980;210(4466):207-10. http://dx.doi.org/10.1126/science.7414331

4. Quillian MR. Word concepts: a theory and simulation of some basic semantic capabilities. Behav Sci. 1967;12(5):410-30. http://dx.doi.org/10.1002/bs.3830120511

5. Tulving E. Memory and consciousness. CanPsychol. 1985; 26(1):1-12. http://dx.doi.org/10.1037/h0080017

6. Alvarez P, Squire LR. Memory consolidation and the medial temporal lobe: a simple network model. Proc Natl Acad Sci USA. 1994;91(15):7041-5. http://dx.doi.org/10.1073/pnas.91.15.7041

7. Damasio AR, Eslinger PJ, Damasio H, Van Hoesen GW, Cornell S. Multimodal amnesic syndrome following bilateral temporal and basal forebrain damage. Arch Neurol. 1985;42(3):252-9. http://dx.doi.org/10.1001/archneur.1985.04060030070012

8. Nadel L, Moscovitch M. Memory consolidation, retrograde amnesia and the hippocampal complex. Curr Opin Neurobiol. 1997;7(2):217-27. http://dx.doi.org/10.1016/S0959-4388(97)80010-4

9. Piolino P, Desgranges B, Belliard S, Matuszewski V, Lalevée C, De la Sayette $V$ et al. Autobiographical memory and autonoetic consciousness: triple dissociation in neurodegenerative diseases. Brain. 2003;1 26(10):2203-19. http://dx.doi.org/10.1093/brain/awg222

10. Butler CR, Zeman AZ. Recent insights into the impairment of memory in epilepsy: transient epileptic amnesia, accelerated long-term forgetting and remote memory impairment. Brain. 2008;131(9):2243-63. http://dx.doi.org/10.1093/brain/awn127

11. Milton F, Muhlert N, Pindus DM, Butler CR, Kapur N, Graham KS et al. Remote memory deficits in transient epileptic amnesia. Brain. 2010;133(5):1368-79. http://dx.doi.org/10.1093/brain/awq055

12. Coras R, Pauli E, Li J, Schwarz M, Rössler K, Buchfelder M et al. Differential influence of hippocampal subfields to memory formation: insights from patients with temporal lobe epilepsy. Brain. 2014;137(7):1945-57. http://dx.doi.org/10.1093/brain/awu100

13. Malloy-Diniz LF, Cruz MF, Torres V, Cosenza R. 0 teste de Aprendizagem Auditivo-Verbal de Rey: normas para uma população brasileira. Rev Bras Neurol. 2000;36(3):79-83.

14. Nitrini R, Lefèvre BH, Mathias SC, Caramelli P, Carrilho PE, Sauaia $\mathrm{N}$ et al. [Neuropsychological tests of simple application for diagnosing dementia]. Arq Neuropsiquiatr. 1994;52(4):457-65. Portuguese. http://dx.doi.org/10.1590/S0004-282X1994000400001

15. Irish M, Lawlor BA, O'Mara SM, Coen RF.Assessment of behavioural markers of autonoetic consciousness during episodic autobiographical memory retrieval: a preliminary analysis. Behav Neurol. 2008;19(1-2):3-6. http://dx.doi.org/10.1155/2008/691925

16. McKhann GM, Knopman DS, Chertkow H, Hyman BT, Jack CR Jr, Kawas $\mathrm{CH}$ et al. The diagnosis of dementia due to Alzheimer's disease: recommendations from the National Institute on
Aging-Alzheimer's Association workgroups on diagnostic guidelines for Alzheimer's disease. Alzheimers Dement. 2011;7(3):263-9. http://dx.doi.org/10.1016/j.jalz.2011.03.005

17. D'Ath P, Katona P, Mullan E, Evans S, Katona C. Screening, detection and management of depression in elderly primary care attenders. I: the acceptability and performance of the 15 item Geriatric Depression Scale (GDS15) and the development of short versions. Fam Pract. 1994;11(3):260-6. http://dx.doi.org/10.1093/fampra/11.3.260

18. Hachinski VC, Iliff LD, Zilhka E, Du Boulay GH, McAllister VL, Marshall $\checkmark$ et al. Cerebral blood flow in dementia. Arch Neurol. 1975;32(9):632-7. http://dx.doi.org/10.1001/archneur.1975.00490510088009

19. Brucki SM, Nitrini R, Caramelli P, Bertolucci PH, Okamoto IH. [Suggestions for utilization of the mini-mental state examination in Brazil]. Arq Neuropsiquiatr. 2003;61(3B):777-81. Portuguese. http://dx.doi.org/10.1590/S0004-282X2003000500014

20. Sunderland T, Hill JL, Mellow AM, Lower BA, Gundersheimer J, Newhouse PA. Clock drawing in Alzheimer's disease: a novel measure of dementia severity. J Am Geriatr Soc. 1989;37(8):725-9.

21. Pfeffer RI, Kurosaki TT, Harrah CH Jr, Chance JM, Filos S. Measurement of functional activities in older adults in the community.J Gerontol. 1982;37(3):323-9. http://dx.doi.org/10.1093/geronj/37.3.323

22. Correia CC, Lima F, Junqueira F, Campos MS, Bastos O, Petribú K et al. AD8-Brazil: cross-cultural validation of the ascertaining dementia interview in Portuguese. J Alzheimers Dis. 2011;27(1):177-85. http://dx.doi.org/10.3233/JAD-2011-100915

23. Beaton DE, Bombardier C, Guillemin F, Ferraz MB. Guidelines for the process of cross-cultural adaptation of self-report measures. Spine. 2000; 25(24):3186-91. http://dx.doi.org/10.1097/00007632-200012150-00014

24. Dall'Ora P, Della Sala S, Spinnler H. Autobiographical memory: its impairment in amnesic syndromes. Cortex. 1989;25(2):197-217. http://dx.doi.org/10.1016/S0010-9452(89)80037-1

25. Greene JDW, Hodges JR, Baddeley AD. Autobiographical memory and executive function in early dementia of Alzheimer type. Neuropsychologia. 1995;33:1647-70.

26. Graham KS, Hodges JR. Differentiating the roles of the hippocampal complex and the neocortex in long-term memory storage: evidence from the study of semantic dementia and Alzheimer's disease. Neuropsychology. 1997;11(1):77-89. http://dx.doi.org/10.1037/0894-4105.11.1.77

27. Hou CE, Miller BL, Kramer JH. Patterns of autobiographical memory loss in dementia. Int J Geriatr Psychiatry. 2005;20(9):809-15. http://dx.doi.org/10.1002/gps.1361

28. Phelps EA. Human emotion and memory: interactions of the amygdala and hippocampal complex. Curr Opin Neurobiol. 2004;14(2):198-202. http://dx.doi.org/10.1016/j.conb.2004.03.015

29. Irish M, Lawlor BA, O'Mara SM, Coen RF. Exploring the recollective experience during autobiographical memory retrieval in amnestic mild cognitive impairment. J Int Neuropsychol Soc. 2010;16(3):546-55. http://dx.doi.org/10.1017/S1355617710000172

30. Irish M, Lawlor BA, O'Mara SM, Coen RF. Impaired capacity for autonoetic reliving during autobiographical event recall in mild Alzheimer's disease. Cortex. 2011;47(2):236-49. http://dx.doi.org/10.1016/j.cortex.2010.01.002 